\title{
Rederivation of Gertler's model and analysis of the Korean economy
}

\author{
Hangsuck Lee ${ }^{a}$, Jihoon Son ${ }^{1, b}$ \\ ${ }^{a}$ Department of Actuarial Science/Mathematics, Sungkyunkwan University, Korea; \\ ${ }^{b}$ Center for Fiscal Projections, Korea Institute of Public Finance, Korea
}

\begin{abstract}
This paper makes a theoretical contribution by providing clear and detailed derivation of economic agents' decision problems including elastic labor supply in Gertler's overlapping generation (OLG) model. We apply the model to the Korean economy by calibration based on Korean economic data. It also analyzes the impact of current social issues such as aging and extension of retirement age, on the Korean economy in a long-run equilibrium. Subsequently, we also discuss the implications of the analysis. Aging has prolonged the period of retirement; therefore, population structure changes by the increase in the proportion of retirees, the total consumption-toGDP ratio decreases, and capital stock increases due to reduced propensity to consume out of wealth in preparation for an individual's retirement life. The implementation of retirement age extension increases the proportion of retirees relatively less and alleviates fluctuations in labor supply and the share of financial assets for both economic agents. However, the decrements in consumption-to-GDP ratio is larger than before, and this leads to a larger rise in the capital stock compared to when there is only an aging effect.
\end{abstract}

Keywords: overlapping generation model, elastic labor supply, aging, life expectancy, retirement age extension, steady-state

\section{Introduction}

This paper builds on Gertler's overlapping generation (OLG) model (1999), which modified the framework proposed by Blanchard (1985) and Weil (1989) allowing for life-cycle behavior. However, we should first consider the relevant precedent literature of OLG models before examining the specifics of Gertler's model. In the basic discrete-time OLG model, Diamond (1965) assumed a two-period lifetime of individuals and considered the life-cycle aspect of human behavior. Using this model, this paper examined the long-term competitive equilibrium in a growth model and explored the effect on the equilibrium of government debt. Diamond assumed a very simple population and age structure to avoid the need for aggregation. In Blanchard (1985)'s continuous-time OLG model, he derived a simple and manageable form of aggregate function by assuming that the probability of death is constant and independent of the consumer's age. This simple form of aggregate functions enabled the relatively easy analysis of: many macroeconomic issues in a steady state, the dynamic effects of fiscal policy, and social insurance. He assumed that economic agents buy actuarial notes, initially suggested by Yaari (1965). Yaari set up a situation in which consumers can address the lifetime uncertainty by purchasing an actuarial note. Weil (1989) abandoned the finite lifetime assumption of OLG models

\footnotetext{
${ }^{1}$ Corresponding author: Center for Fiscal Projections, Korea Institute of Public Finance, Korea 336 Sicheong-daero, Sejong 30147, South Korea. E-mail: jihoonson13@gmail.com

Published 30 November 2020 / journal homepage: http://csam.or.kr

(C) 2020 The Korean Statistical Society, and Korean International Statistical Society. All rights reserved.
} 
and developed a model of infinitely-lived households based on the hypothesis that new cohorts enter the economy over time.

Gertler (1999) developed an analytically tractable OLG model that employs life-cycle behavior. In Gertler's model, the aggregate consumption function can be derived by imposing constant transition probabilities per period from work to retirement, from retirement to death and adopting Farmer (1990)'s non-expected utility functions. It is also possible to analyze impact of social security and fiscal policies on changes in consumption, labor supply, and share of assets. of workers and retirees in the steady-state equilibrium.

In Gertler's model, there are two state endogenous variables such as capital stock and the share of financial assets. The change in the share of financial assets of economic agents due to demographic changes or policy changes can explain the transfer of wealth between workers and retirees. Consumptions depends on the propensity to consume out of wealth and financial and non-financial assets held by each economic agent. In addition, policy variables such as government debt, government expenditure and social security payments are exogenous variables.

Some studies have since conducted out calibration using data from specific countries or have extended Gertler's (1999) model. Keuschnigg and Keuschnigg (2004) assumed an inelastic labor market where only workers supply labor. They presented an extension model to incorporate an endogenous labor supply combined with search unemployment as well as analyzed the effects of aging and pension reform on the economy of Austria. Kilponen et al. (2006) extended Gertler's model, making the analysis of the effects of distortionary taxation and demographic uncertainty possible. They analyzed the long-run effects of aging and dynamic effects of variation in the demographic structure of the economy of Finland. Grafenhofer et al. (2006) introduced the concept of probabilistic aging in a generalized OLG model. This model allowed for more age life-cycle groups as well as analyzed demographic changes including increasing life expectancy and a temporary baby boom. Rahman (2008) added demographic uncertainty to Gertler's model and analyzed the effects of uncertain population growth under alternative public pension systems.

The main difference from Gertler's and subsequent relevant research papers is that this paper takes a major step with a clearer derivation of economic agents' decision problems that include an elastic labor supply. Gertler focused significant attention on the case of inelastic labor supply, the theoretical development of economic agents' decision problems including elastic labor supply was relatively ambiguous and he did not carry out various analyses with regard to that. Subsequent research papers were empirical papers that applied the economy of particular countries to the Gertler's model, rather than clarifying the theory. It is also meaningful that we attempt to apply Gertler's model to the Korean economy for the first time and we analyze the effects of aging and retirement age extension, in the face of intensifying population aging.

The structure of the paper is as follows: Section 2 introduces the basic assumptions in Gertler (1999) that used in this paper: population dynamics, actuarial note, and preferences. Section 3 deals with the problem of individual choice to derive the behavior of individual consumption. Section 4 deals with the problem of aggregation choice based on the results of individual choice and derives steady-state equations, and steady-state results of the Korean economy. In addition, the distribution of wealth between groups and assumption of production are also dealt with. Section 5 conducts two sensitivity analyses on the impact of aging and the extension of retirement age. Section 6 concludes by summarizing implications and pointing out the limitations of this paper.

\section{Basic assumptions}

In this section, we briefly introduce the basic assumptions in Gertler (1999) used in this paper. Indivi 
Table 1: Probabilities of transition

\begin{tabular}{lcc}
\hline \hline & Worker & Retiree \\
\hline Survival rate & N/A & $\gamma$ \\
Mortality rate & N/A & $1-\gamma$ \\
Probability of remaining in labor force in the next period & $\omega$ & $\gamma$ \\
Probability of exit from labor force in the next period & $1-\omega$ & $1-\gamma$ \\
\hline \hline
\end{tabular}

Notes: Each transition probability is greater than zero and less than one.

duals' life is a finite and their stages of life are distinguished by work and retirement. There are also two types of economic agents: a worker and a retiree. The flow of time is divided into successive periods and the unit of time denoted by $t$ is in year. There are three kinds of assumptions in this model to derive a tractable total consumption function as: population dynamics, actuarial note, and preferences.

\subsection{Population dynamics}

The transition from work to retirement or from retirement to death is determined stochastically. Each individual is born a worker and he is transferred to maintaining status of a worker or to retirement in the next period by transition probability, $\omega$ or $1-\omega$, respectively $(0<\omega<1)$. The probability of survival or death for a worker do not need to be consider because it is assumed that the death of the individual begins once he retires. A retiree survives with a probability of $\gamma$ or is transferred to a state of death with a probability of $1-\gamma(0<\gamma<1)$ (Table 1$)$. The remaining expected working period of a worker is $1 /(1-\omega)$ and the remaining life expectancy of a retiree is $1 /(1-\gamma)$ on the assumption that the transition probability is independent of employment tenure or age.

Let $N_{t}$ denote the number of workers in period $t$ and assumed to grow at the constant rate, $n(n>0)$. Workers in period $t+1$ consist of workers who have maintained their status since time $t$ and new workers who are born in $t+1$. Therefore, the number of new workers at $t+1$ is $(1-\omega+n) N_{t}$.

$$
N_{t+1}=(1+n) N_{t}=\omega N_{t}+(1-\omega+n) N_{t} .
$$

A ratio of retirees to workers $\psi$ can be derived by using the following equations (2.2) and the ratio is fixed in the stationary equilibrium. Then the number of retirees at time $t$ is $\psi N_{t}$ and the number of retirees grows at the rate $n$, like the growth rate of workers.

$$
\begin{gathered}
\sum_{s=1}^{\infty} \gamma^{s-1}(1-\omega) N_{t-s}=\sum_{s=1}^{\infty} \gamma^{s-1}(1-\omega) \frac{N_{t}}{(1+n)^{s}}=\frac{(1-\omega) N_{t}}{1+n} \sum_{s=1}^{\infty}\left(\frac{\gamma}{1+n}\right)^{s-1}=\frac{(1-\omega) N_{t}}{1+n-\gamma} \\
\psi=\frac{(1-\omega)}{1+n-\gamma} .
\end{gathered}
$$

\subsection{Actuarial note}

The notion of an actuarial note was initially introduced by Yaari (1965), and then applied to the models of Blanchard (1985) and Gertler (1999). An actuarial note is intended to eliminate the impact of uncertain life span. When the person who purchase the actuarial note dies, the person's property is attributed to the insurance company and distributed to the rest of survivors. Therefore, survivors persons can get higher returns than the normal returns on the assets they entrust. An actuarial note in this model limited to retirees and under the arrangement each retiree buys an actuarial note. For a retiree, the fraction $\gamma$ of those that survive to the next period receive all the returns, while the fraction 


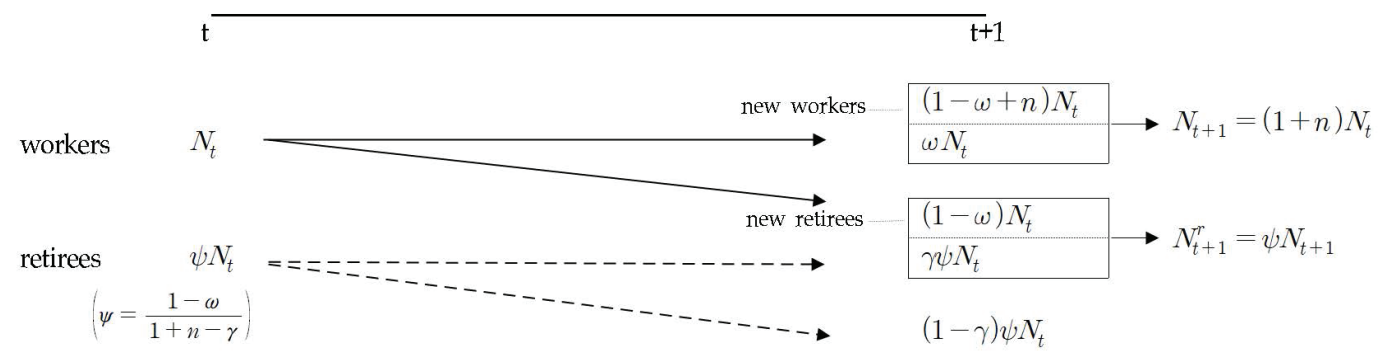

Figure 1: Population dynamics by transition probability.

$1-\gamma$ who die receive nothing. Each surviving retiree receives a return in proportion to his initial wealth. Therefore, for example, if $\mathrm{R}$ is the gross return on assets, a surviving retiree's gross return on wealth is $R / \gamma$.

\subsection{Preferences}

To address an income risk, individuals are assumed to be preferred to separate risk aversion from intertemporal substitution. The assumption of risk neutrality is reasonable in that it mitigates the impact of income variation that occurs on the assumption of constant probability of transition in the model. Therefore, we adopt a non-expected utility function proposed by Farmer (1990) that limit individuals to have risk neutrality in relation income risk, but to be arbitrary with respect to intertemporal elasticity of substitution. $V_{t}^{i}$ is an individual's value function, where the superscript $i=w, r$ denotes a worker $(w)$ or a retiree $(r)$ respectively. An individual derives utility from consumption $C_{t}$, leisure $1-l_{t}$, where $l_{t}$ is the fraction of working time at time $t$ by an agent. $\beta$ is a subjective discount factor and $\gamma$ is a retiree's survival rate for each period. Then, value function of an individual is given by:

$$
V_{t}^{i}=\left[\left\{\left(C_{t}^{i}\right)^{v}\left(1-l_{t}^{i}\right)^{1-v}\right\}^{\rho}+\beta^{i}\left\{E_{t}\left(V_{t+1} \mid i\right)\right\}^{\rho}\right]^{\frac{1}{\rho}}
$$

with

$$
\beta^{w}=\beta, \quad \beta^{r}=\beta \gamma,
$$

where $E_{t}\left(V_{t+1} \mid i\right)$ is the expected value of next period's value function, conditional on the person being type $i$ at $t$ and being alive at $t+1$.

$$
\begin{aligned}
E_{t}\left(V_{t+1} \mid w\right) & =\omega V_{t+1}^{w}+(1-\omega) V_{t+1}^{r}, \\
E_{t}\left(V_{t+1} \mid r\right) & =V_{t+1}^{r} .
\end{aligned}
$$

The retiree's effective intertemporal subjective discount factor is $\beta \gamma$ the survival rate until the next period is $\gamma$. We consider the expected value of value function in the next period on the assumption that the retiree is alive in the next period. Meanwhile, the curvature parameter $\rho$ introduces a smooth tradeoff for individuals between intertemporal consumption. The intertemporal elasticity of substitution, $\sigma=1 /(1-\rho)$, is a finite and choice of $\sigma$ is flexible under this preference structure.

\section{Individual choice}

In this paper, each individual worker as well as retirees both have a labor-leisure choice for one unit of time per period under an elastic labor supply. Wage levels depend on labor productivity; therefore, 
it is assumed that a retiree receive relatively low wages compared to that of a worker. Let $\xi \in(0,1)$ be the productivity of labor supplied by a retiree relative to a worker and then the wage per unit of time is as: $W^{w}=W, W^{r}=\xi W$. And there is a government that implement fiscal and social security policies. Social security benefits are paid only to a retiree and taxes are levied only on a worker to finance government policies.

\subsection{Consumption by retirees}

Retirees choose consumption, leisure that maximize their value function

$$
V_{t}^{r}=\left[\left\{\left(C_{t}^{r}\right)^{v}\left(1-l_{t}^{r}\right)^{1-v}\right\}^{\rho}+\beta \gamma\left(V_{t+1}^{r}\right)^{\rho}\right]^{\frac{1}{\rho}}
$$

subject to budget constraint

$$
A_{t+1}^{r}=\frac{R_{t}}{\gamma} A_{t}^{r}+W_{t}^{r} l_{t}^{r}+E_{t}-C_{t}^{r}
$$

Financial assets $A_{t}^{r}$ at the beginning of time period from $t$ and $t+1$ evolve according to Equation (3.2) where $R_{t} / \gamma$ is the gross return applied to retirees buying actuarial notes and surviving up to $t+1, W_{t}^{r} l_{t}^{r}$ is labor income, $E_{t}$ is social security benefits from the government, $C_{t}^{r}$ is consumption, at the end of the period.

Retirees consume current assets including financial and non-financial assets. Non-financial assets include human wealth $H_{t}^{r}$ that is the present value of the future labor income and social security wealth $S_{t}^{r}$ that is the present value of future social security benefits including time t-point. The retiree's nonfinancial assets can be evaluated as

$$
\begin{aligned}
& H_{t}^{r}=W_{t}^{r} l_{t}^{r}+\frac{\gamma}{R_{t+1}} H_{t+1}^{r}, \\
& S_{t}^{r}=E_{t}+\frac{\gamma}{R_{t+1}} S_{t+1}^{r} .
\end{aligned}
$$

By solving the optimization problem, we have following equations (Appendix (A.7))

$$
1-l_{t}^{r}=\frac{1-v}{v} \frac{C_{t}^{r}}{W_{t}^{r}},
$$

and from Equation (3.5), we obtain labor supply curve $l_{t}^{r}$ for retirees.

The consumption Euler equation for the retiree yields (Appendix (A.17))

$$
C_{t+1}^{r}=\left[\left(\frac{W_{t}^{r}}{W_{t+1}^{r}}\right)^{(1-v) \rho} R_{t+1} \beta\right]^{\sigma} C_{t}^{r} .
$$

Let us guess a form of consumption function as:

$$
C_{t}^{r}=\varepsilon_{t} \pi_{t}\left(\frac{R_{t}}{\gamma} A_{t}^{r}+H_{t}^{r}+S_{t}^{r}\right),
$$

where $\varepsilon_{t} \pi_{t}$ is the retiree's propensity to consume out of wealth. And $\varepsilon_{t} \pi_{t}$ is derived by (Appendix (A.23))

$$
\varepsilon_{t} \pi_{t}=1-\left[\left(\frac{W_{t}^{r}}{W_{t+1}^{r}}\right)^{1-v} R_{t+1}\right]^{\sigma-1} \beta^{\sigma} \gamma \frac{\varepsilon_{t} \pi_{t}}{\varepsilon_{t+1} \pi_{t+1}} .
$$

$\varepsilon_{t}$ is the ratio of two propensity to consume, which can be interpreted as the elasticity of the retiree's consumption with respect to the worker's consumption. 


\subsection{Consumption by workers}

Workers choose consumption, leisure that maximize their value function

$$
V_{t}^{w}=\left[\left\{\left(C_{t}^{w}\right)^{v}\left(1-l_{t}^{w}\right)^{1-v}\right\}^{\rho}+\beta\left\{\omega V_{t+1}^{w}+(1-\omega) V_{t+1}^{r}\right\}^{\rho}\right]^{\frac{1}{\rho}}
$$

subject to budget constraint

$$
A_{t+1}^{w}=R_{t} A_{t}^{w}+W_{t} l_{t}^{w}-C_{t}^{w}
$$

Financial assets $A_{t}^{w}$ at the beginning of time period $t$ and $t+1$ evolve according to Equation (3.10) where $R_{t}$ is the gross return, $W_{t} l_{t}^{w}$ is after-tax labor income, $C_{t}^{r}$ is consumption, at the end of the period. Workers do not receive social security benefits during the working period, but once they retire, they will receive from then on.

As with retirees, workers consume out of current assets including financial and non-financial assets. On the other hand, valuation of non-financial assets for workers should consider both different future cash-flows depending on two possibilities of maintaining a worker's status and retiring by transition probabilities. Therefore, the worker's non-financial assets, human wealth $H_{t}^{w}$ and social security wealth $S_{t}^{w}$, are evaluated by

$$
\begin{aligned}
& H_{t}^{w}=W_{t} l_{t}^{w}+\frac{\omega}{R_{t+1} \Omega_{t+1}} H_{t+1}^{w}+\frac{1-\omega}{R_{t+1} \Omega_{t+1}} H_{t+1}^{r}, \\
& S_{t}^{w}=\frac{\omega}{R_{t+1} \Omega_{t+1}} S_{t+1}^{w}+\frac{1-\omega}{R_{t+1} \Omega_{t+1}} \varepsilon_{t+1} S_{t+1}^{r}
\end{aligned}
$$

using two discounting factor depending on the two cases of work and retirement. In Gertler (1999), $S_{t+1}^{r}$ is defined as the social security wealth per beneficiary at $t+1$ and $\varepsilon_{t+1}$ is interpreted as the value that workers are able to consume today from social security wealth to be received after retirement.

In the worker-decision making problems, the leisure equations and consumption Euler equation for the worker are derived as: (Appendix (B.7) and (B.18))

$$
\begin{gathered}
1-l_{t}^{w}=\frac{1-v}{v} \frac{C_{t}^{w}}{W_{t}}, \\
\omega C_{t+1}^{w}+(1-\omega) \chi\left(\varepsilon_{t+1}\right)^{\frac{\sigma}{1-\sigma}} C_{t+1}^{r}=\left[\left(\frac{W_{t}}{W_{t+1}}\right)^{1-v}\right]^{\sigma-1}\left(R_{t+1} \Omega_{t+1} \beta\right)^{\sigma} C_{t}^{w} .
\end{gathered}
$$

In Equation (3.12), $\Omega_{t+1}$ is a adjusting discount factor $1 / R_{t+1}$ and is given by (Appendix (B.17))

$$
\Omega_{t+1}=\omega+(1-\omega)\left(\varepsilon_{t+1}\right)^{\frac{1}{1-\sigma}} \chi
$$

where $\chi=(1 / \xi)^{1-v}, \xi=W_{t+1}^{r} / W_{t+1}$.

On the assumption that every worker consumes the fraction $\pi_{t}$ of his wealth, we conjecture a form of consumption function that is analogous with the retiree's as:

$$
C_{t}^{w}=\pi_{t}\left(R_{t} A_{t}^{w}+H_{t}^{w}+S_{t}^{w}\right)
$$

where $\pi_{t}$ is given by (Appendix (B.24))

$$
\pi_{t}=1-\left[\left(\frac{W_{t}}{W_{t+1}}\right)^{1-v} R_{t+1} \Omega_{t+1}\right]^{\sigma-1} \beta^{\sigma} \frac{\pi_{t}}{\pi_{t+1}} .
$$




\section{Aggregation choice}

\subsection{Aggregate consumption and distribution of wealth}

Since individuals within group have the same propensity to consume out of wealth, one can simply sum (3.7) and (3.16) across individual retirees/workers to derive the aggregate consumption function by groups as:

$$
\begin{aligned}
C_{t}^{r \cdot} & =\varepsilon_{t} \pi_{t}\left(R_{t} A_{t}^{r \cdot}+H_{t}^{r \cdot}+S_{t}^{r^{*}}\right)=\varepsilon_{t} \pi_{t}\left(R_{t} \lambda_{t}^{r} A_{t}^{r \cdot}+H_{t}^{r \cdot}+S_{t}^{r \cdot}\right), \\
C_{t}^{w^{*}} & =\pi_{t}\left(R_{t} A_{t}^{w^{*}}+H_{t}^{w^{*}}+S_{t}^{w^{*}}\right)=\pi_{t}\left[R_{t}\left(1-\lambda_{t}^{r}\right) A_{t}^{\cdot}+H_{t}^{w^{*}}+S_{t}^{w^{*}}\right] .
\end{aligned}
$$

In (4.1), (4.2), $\lambda_{t}^{r} \equiv A_{t}^{r \cdot} / A_{t}^{*}$ and $\lambda_{t}^{w} \equiv\left(1-\lambda_{t}^{r}\right) \equiv A_{t}^{w \cdot} / A_{t}^{*}$ denote the share of assets held by retirees and workers respectively. The gross return on financial assets of retirees in (4.1) is $R_{t}$ because the surviving retirees are the fraction $\gamma$ of the total number of retirees.

Then, (4.1) and (4.2) are combined to obtain the following aggregate consumption function:

$$
C_{t}^{*}=\pi_{t}\left[\left\{1+\left(\varepsilon_{t}-1\right) \lambda_{t}^{r}\right\} R_{t} A_{t}^{\cdot}+H_{t}^{w \cdot}+S_{t}^{w \cdot}+\varepsilon_{t}\left(H_{t}^{r \cdot}+S_{t}^{r \cdot}\right)\right] .
$$

The aggregate human wealth and social security wealth equations of retirees are given by

$$
\begin{aligned}
& H_{t}^{r}=W_{t}^{r} L_{t}^{r}+\frac{\gamma}{(1+n) R_{t+1}} H_{t+1}^{r .}, \\
& S_{t}^{r \cdot}=E_{t}^{*}+\frac{\gamma}{(1+n) R_{t+1}} S_{t+1}^{r} .
\end{aligned}
$$

Which are derived from summing (3.3) and (3.4) over individual retirees. Since the workforce increases by $(1+n)$ over the period, it is necessary to adjust the value of future non-financial assets at $t+1$ to the $t$-point value by using the dividing factor $(1+n)$.

For workers, the aggregate human wealth and social security wealth equations are given by

$$
\begin{aligned}
H_{t}^{w \cdot} & =W_{t} L_{t}^{w}-T_{t}+\frac{\omega}{(1+n) R_{t+1} \Omega_{t+1}} H_{t+1}^{w \cdot}+\frac{1-\omega}{(1+n) R_{t+1} \Omega_{t+1}} H_{t+1}^{r}, \\
S_{t}^{w \cdot} & =\frac{\omega}{(1+n) R_{t+1} \Omega_{t+1}} S_{t+1}^{w \cdot}+\frac{1-\omega}{R_{t+1} \Omega_{t+1}} \frac{\varepsilon_{t+1}}{(1+n) \psi} S_{t+1}^{r} .
\end{aligned}
$$

Which are respectively derived from summing (3.11), (3.12) over individual workers. In (4.6), the total labor income of all workers $W_{t} L_{t}^{w}$ is pre-tax income; therefore, the total tax on labor income for all workers $T_{t}$ should be deducted. As moving between groups by transition probability, the distribution of financial wealth evolves over time and a change in distribution of financial wealth will influence each group's total consumption demand.

Now we derive the equation of the share of financial assets by groups $\lambda_{t}^{i}$, and examine the evolution of the distribution of wealth. The total financial assets held by workers at $t+1,\left(1-\lambda_{t+1}^{r}\right) A_{t+1}^{*}$, equal assets accumulated by workers at $t$ for $t+1$ times the probability of remaining in workforce in the next period $\omega$, as:

$$
\left(1-\lambda_{t+1}^{r}\right) A_{t+1}^{\cdot}=\omega\left[\left(1-\lambda_{t}^{r}\right) R_{t} A_{t}^{\cdot}+W_{t} L_{t}^{w}-T_{t}-C_{t}^{w^{*}}\right] .
$$

Which can be rewritten as

$$
R_{t} \lambda_{t}^{w} A_{t}^{\cdot}+W_{t} L_{t}^{w}-T_{t}-C_{t}^{w \cdot}=\frac{1-\lambda_{t+1}^{r}}{\omega} A_{t+1}
$$




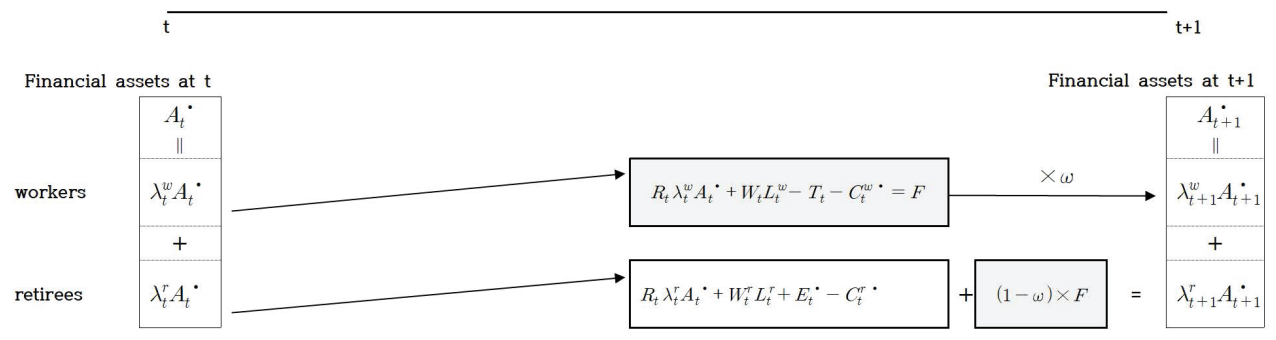

Figure 2: Change in the share of assets by economic agents from $t$ to $t+1$.

In (4.8), the square bracket means workers' assets before distribution by movement from workers to retirees by transition probability and workers' total savings at the end of time $t$.

The total financial assets owned by retirees at the beginning of time $t+1$ depends on both the saving of current retirees at $t$ and the assets of workers at $t$ who make the transition to retirement at $t+1$. The total assets held by retirees at $t+1, \lambda_{t+1}^{r} A_{t+1}^{*}$, equal to sum assets accumulated by existing retirees and assets carried by new retirees. Therefore, the equation for the total financial assets held by retirees at $t+1$ is derived as:

$$
\lambda_{t+1}^{r} A_{t+1}^{\cdot}=R_{t} \lambda_{t}^{r} A_{t}^{\cdot}+W_{t}^{r} L_{t}^{r}+E_{t}^{\cdot}-C_{t}^{r \cdot}+(1-\omega) \times\left(R_{t} \lambda_{t}^{w} A_{t}^{\cdot}+W_{t} L_{t}^{w}-T_{t}-C_{t}^{w \cdot}\right) .
$$

By using (4.9), (4.10) can be rewritten as

$$
\lambda_{t+1}^{r} A_{t+1}^{\cdot}=R_{t} \lambda_{t}^{r} A_{t}^{\cdot}+W_{t}^{r} L_{t}^{r}+E_{t}^{*}-C_{t}^{r \cdot}+(1-\omega) \frac{1-\lambda_{t+1}^{r}}{\omega} A_{t+1}^{\cdot}
$$

Summarize the equation for $\lambda_{t+1}^{r}$ after putting (4.1) into (4.11), then the share of wealth held by retirees evolves according to

$$
\lambda_{t+1}^{r}=\omega\left(1-\varepsilon_{t} \pi_{t}\right) R_{t} \lambda_{t}^{r} \frac{A_{t}^{*}}{A_{t+1}^{\cdot}}+\omega\left[W_{t}^{r} L_{t}^{r}+E_{t}^{*}-\varepsilon_{t} \pi_{t}\left(H_{t}^{r \cdot}+S_{t}^{r}\right)\right] \frac{1}{A_{t+1}^{\cdot}}+(1-\omega) .
$$

\subsection{Production and government factors}

Under a closed and a competitive economy, the total production $Y_{t}$ is given by a Cobb-Douglas production function that is a standard form for production as:

$$
Y_{t}=\left(X_{t} N_{t}\right)^{\alpha} K_{t}^{1-\alpha} .
$$

There are two inputs to the production function: labor $N$ and capital $K$. Capital depreciates at the rate $\delta$, and the parameter $\alpha$ and $1-\alpha$ are the output elasticities of labor and capital, respectively. Technology $X$ is labor-augmenting and grows exogenously by $x$ and $X_{t}^{\alpha}$ is a total factor productivity.

$$
X_{t+1}=(1+x) X_{t} .
$$

On the assumption that both workers and retirees supply labor elastically, the maximum workforce available and the workforce actually supplied do not always coincide. Therefore, total output is now given by

$$
Y_{t}=\left(X_{t} L_{t}\right)^{\alpha} K_{t}^{1-\alpha},
$$


where

$$
L_{t}=L_{t}^{w}+\xi L_{t}^{r}
$$

Aggregate labor supply equations of workers and retirees obtained by simply summing individual labor supply equations (3.5), (3.13) are respectively given by

$$
\begin{aligned}
L_{t}^{w} & =N_{t}-\frac{(1-v) / v}{W_{t}} C_{t}^{w}, \\
L_{t}^{r} & =N_{t} \psi-\frac{(1-v) / v}{W_{t}} C_{t}^{r} .
\end{aligned}
$$

Equation (4.15) implies that wages and total return on capital equations are given by

$$
\begin{aligned}
W_{t} & =\frac{\alpha Y_{t}}{L_{t}}, \\
R_{t} & =\frac{(1-\alpha) Y_{t}}{K_{t}}+(1-\delta) .
\end{aligned}
$$

However, there is a government that implements fiscal and social security policies. Each period, the government consumes $G_{t}$ and pays retirees a total of social security benefits, $E_{t}$. To finance the expenditure, government issues one period government bonds, $B_{t+1}$ and levies a total of tax, $T_{t}$. Therefore, the stock of government debt at the beginning of time $t+1$ is given by

$$
B_{t+1}=R_{t} B_{t}+G_{t}+E_{t}-T_{t}
$$

By iterating equation (4.21), the inter-temporal budget constraint is as given by

$$
R_{t} B_{t}=\sum_{v=0}^{\infty} \frac{T_{t+v}}{\prod_{z=1}^{v} R_{t+z}}-\sum_{v=0}^{\infty} \frac{G_{t+v}}{\prod_{z=1}^{v} R_{t+z}}-\sum_{v=0}^{\infty} \frac{E_{t+v}}{\prod_{z=1}^{v} R_{t+z}}
$$

The present value of the outstanding debt is equal to the present value of the total amount of government expenditure not covered by taxes for each period. Assume that the government adjusts taxes with other government policies fixed to satisfy equation (4.22). The ratio of government consumption to output $\bar{g}_{t}$, the ratio of social security payments to output, $\bar{e}_{t}$, and the stock of government bonds to output, $\bar{b}_{t}$ is assumed to be fixed as:

$$
G_{t}=\bar{g}_{t} Y_{t}, \quad E_{t}=\bar{e}_{t} Y_{t}, \quad B_{t}=\bar{b}_{t} Y_{t}
$$

Financial wealth equals the sum of capital and government debt,

$$
A_{t}=K_{t}+B_{t}
$$

and which are the vehicle for saving and the capital intensity evolves as

$$
K_{t+1}=Y_{t}-C_{t}-G_{t}+(1-\delta) K_{t}
$$




\subsection{Equations for steady-state values}

In this section, the steady-state equations are derived to calculate the steady-state values in the longrun equilibrium from the aggregate functions introduced in the previous sections. An analysis of the steady-state values is needed to see how the life-cycle aspects of the model affect the economic agents' behavior. The method of deriving the steady-state equations is followed by Gertler (1999), and all steady-state variables are denoted by the normalized certain variables relative to output. For example, the ratio of capital to output is denoted by $k=K / Y$. In the steady state, all quantity variables grow exogenously at the effective labor force growth rate, $(1+x)(1+n)$.

First, let initial values to be $R, \Omega, L_{w} / N, L_{w} / L$ and by using equation

$$
R=(1-\alpha) k^{-1}+(1-\delta) .
$$

Then we have initial capital intensity from (4.26)

$$
k=\frac{1-\alpha}{R-1+\delta},
$$

which is tentatively determined. Next, the ratio of total tax to output $\tau$ can be determined

$$
\tau=[R-(1+x)(1+n)] b+g+e .
$$

For each worker and retiree, we have following steady-state values of the propensity to consume out of wealth equations as:

$$
\begin{gathered}
\pi=1-\left[\left(\frac{1}{1+x}\right)^{1-v} R \Omega\right]^{\sigma-1} \beta^{\sigma}, \\
\varepsilon \pi=1-\left[\left(\frac{1}{1+x}\right)^{1-v} R\right]^{\sigma-1} \beta^{\sigma} \gamma .
\end{gathered}
$$

Hence, elasticity of retiree's consumption $\varepsilon$ is determined.

Workers' and retirees' human wealth can be evaluated as

$$
\begin{aligned}
h^{w} & =\left[\alpha \frac{L^{w}}{L}-\tau+\frac{(1-\omega)(1+x)}{R \Omega} h^{r}\right] /\left(1-\frac{\omega(1+x)}{R \Omega}\right), \\
h^{r} & =\alpha \frac{L-L^{w}}{L} /\left(1-\frac{\gamma(1+x)}{R}\right)
\end{aligned}
$$

by using recursive human wealth equation, respectively

$$
\begin{aligned}
h^{w} & =\alpha \frac{L^{w}}{L}-\tau+\frac{\omega(1+x)}{R \Omega} h^{w}+\frac{(1-\omega)(1+x)}{R \Omega} h^{r}, \\
h^{r} & =\alpha \frac{L-L^{w}}{L}+\frac{\gamma(1+x)}{R} h^{r} .
\end{aligned}
$$

Workers' and retirees' social security wealth can be evaluated as

$$
\begin{aligned}
S^{w} & =\frac{(1-\omega)(1+x)}{R \Omega} \frac{\varepsilon}{\psi} S^{r} /\left(1-\frac{\omega(1+x)}{R \Omega}\right), \\
S^{r} & =e /\left(1-\frac{\gamma(1+x)}{R}\right)
\end{aligned}
$$


by using recursive social security wealth equation, respectively

$$
\begin{aligned}
S^{w} & =\frac{\omega(1+x)}{R \Omega} S^{w}+\frac{(1-\omega)(1+x)}{R \Omega} \frac{\varepsilon}{\psi} S^{r}, \\
S^{r} & =e+\frac{\gamma(1+x)}{R} S^{r} .
\end{aligned}
$$

Next, steady-state values of the share of assets for each agent can be expressed and solved in

$$
\begin{aligned}
& \lambda^{w}=1-\lambda^{r}, \\
& \lambda^{r}=\frac{\omega\left[\alpha \frac{L-L^{w}}{L}+e-\varepsilon \pi\left(h^{r}+s^{r}\right)\right](k+b)^{-1}+(1-\omega)(1+x)(1+n)}{(1+x)(1+n)-\omega R(1-\varepsilon \pi)} .
\end{aligned}
$$

The steady-state version of each aggregate consumption amounts can be

$$
\begin{aligned}
c^{w} & =\pi\left[\left(1-\lambda^{r}\right) R(k+b)+h^{w}+s^{w}\right], \\
c^{r} & =\varepsilon \pi\left[\lambda^{r} R(k+b)+h^{r}+s^{r}\right],
\end{aligned}
$$

and aggregation equation will be

$$
c=\pi\left\{\left[\left(1+(\varepsilon-1) \lambda^{r}\right] R(k+b)+h^{w}+s^{w}+\varepsilon\left(h^{r}+s^{r}\right)\right\},\right.
$$

which can be used in calculating capital intensity such that

$$
[(1+x)(1+n)-1+\delta] k=1-c-g .
$$

Placing (4.43) into (4.44), then we have

$$
[(1+x)(1+n)-1+\delta] k=1-\pi\left\{\left[1+(\varepsilon-1) \lambda^{r}\right] R(k+b)+h^{w}+s^{w}+\varepsilon\left(h^{r}+s^{r}\right)\right\}-g .
$$

Hence, we have new recursive values

$$
R=\frac{1-[(1+x)(1+n)-1+\delta] k-\pi\left[h^{w}+s^{w}+\varepsilon\left(h^{r}+s^{r}\right)\right]-g}{\pi\left[1+(\varepsilon-1) \lambda^{r}\right](k+b)}
$$

and the worker's risk adjusted factor and steady-state value related to labor supply are as follows

$$
\begin{aligned}
\Omega & =\omega+(1-\omega)\left(\varepsilon_{t+1}\right)^{\frac{1}{1-\sigma}} \chi, \\
\frac{L^{w}}{L} & =\frac{N}{L}-\frac{(1-v) / v}{\alpha} c^{w}, \\
\frac{L}{N} & =(1+\xi \psi)\left[1+\frac{(1-v) / v}{\alpha} c\right]^{-1}
\end{aligned}
$$

used in minimizing the distance measure of initial and new values of $R$ and $\Omega, L_{w} / N, L_{w} / L$.

\section{Application to the Korean economy}

\subsection{Data and steady-state values}

We choose the following exogenous parameters that reflect the economic features of Korea (Table

2). Some of the values for the exogenous nonpolicy parameters such as preference parameter for 
Table 2: Definition of parameter values

\begin{tabular}{|c|c|c|c|}
\hline Parameter & Value & Assumption or calculation method & Source \\
\hline$n$ & 0.01 & $\begin{array}{l}\text { Workforce growth rate : } \\
\text { 3-year (2016-2018) average of the growth rate of working age } \\
\text { population aged } 20 \text { to } 64 \text {. }\end{array}$ & $\begin{array}{l}\text { The economically active } \\
\text { population survey, Statis- } \\
\text { tics Korea. }\end{array}$ \\
\hline$\omega$ & 0.94 & $\begin{array}{l}\text { Probability of remaining a worker in the next period: } \\
\text { the remaining time in the labor force for a representative } \\
\text { worker with an age of } 42 \text { is } 18 \text { years. }(1 /(1-\omega)=18)\end{array}$ & \\
\hline$\gamma$ & 0.92 & $\begin{array}{l}\text { Probability of surviving of a retiree to the next period: the } \\
\text { remaining life expectancy of a representative retiree with an } \\
\text { age of } 71 \text { is } 12 \text { years. }(1 /(1-\gamma=12)\end{array}$ & \\
\hline$v$ & 0.4 & preference parameter for consumption & Gertler (1999) \\
\hline $1-v$ & 0.6 & preference parameter for leisure & Gertler (1999) \\
\hline$\beta$ & 1 & subjective discount rate & Gertler (1999) \\
\hline$\rho$ & -3 & the curvature parameter & Gertler (1999) \\
\hline$\sigma$ & 0.25 & intertemporal elasticity of substitution & Gertler (1999) \\
\hline$\xi$ & 0.6 & $\begin{array}{l}\text { productivity of a unit of labor supplied by a retiree relative to } \\
\text { a worker }\end{array}$ & Gertler (1999) \\
\hline$\alpha$ & 0.628 & $\begin{array}{l}\text { Labor income share ratio : 3-year (2016-2018) average of the } \\
\text { labor income share ratio }\end{array}$ & $\begin{array}{l}\text { National accounts, } \\
\text { the Bank of Korea }\end{array}$ \\
\hline$\delta$ & 0.1 & capital depreciation rate & Gertler (1999) \\
\hline$x$ & 0.014 & $\begin{array}{l}\text { Growth rate of technology : derived from the 3-year (2016- } \\
\text { 2018) average of the total factor productivity growth rate by } \\
\text { using formula, TFP }=x^{\alpha} \text {. }\end{array}$ & \\
\hline$b$ & 0.36 & $\begin{array}{l}\text { Government debt to output : 2-year average of the government } \\
\text { debt to output (Table 3) }\end{array}$ & $\begin{array}{l}\text { Electronic national index, } \\
\text { Ministry of Economy and } \\
\text { Finance }\end{array}$ \\
\hline$g$ & 0.15 & $\begin{array}{l}\text { Government consumption to output : 2-year average of gov- } \\
\text { ernment expenditure which is the sum of mandatory (excluding } \\
\text { social security payments and interest) and discretionary expen- } \\
\text { diture (Table 3) }\end{array}$ & $\begin{array}{l}\text { The FY2017 Accounting } \\
\text { Analysis Series I, National } \\
\text { Assembly Budget Office }\end{array}$ \\
\hline$e$ & 0.015 & $\begin{array}{l}\text { Social security payments to output : 2-year average of social } \\
\text { security payments to output composed of the Old-age Pension, } \\
\text { Disability Pension and Survivor Pension in National Pension } \\
\text { Scheme and the Basic Pension (Table 3) }\end{array}$ & $\begin{array}{l}\text { The FY2017Accounting } \\
\text { Analysis Series I, Na- } \\
\text { tional Assembly Budget } \\
\text { Office }\end{array}$ \\
\hline
\end{tabular}

consumption, subjective discount, depreciation rate, intertemporal preference, labor productivity of a retiree are the same as Gertler choose (Gertler, 1999). Other parameters are set using recent statistics obtainable from official sources of Korea.

The workforce growth rate is set at 0.01 using a 3-year average of recent data obtained from The Statistics Korea and National Accounts. The labor income share ratio is set at 0.628 and the growth rate of technology is set at 0.014 using a 3-year average of recent data obtained from The Bank of Korea. Policy parameters such as the ratio of government debt to output, the ratio of government consumption to output and the ratio of social security payments to output is set at $0.36,0.15$, and 0.015, respectively using a 2-year average of data obtained from government institutions (Table 3 ).

Table 4 displays the steady-state values of variables when applying the exogenous parameter values in Table 2 to the model. In steady-state, the capital-output ratio is 2.10 , the capital stock per unit of effective labor is 3.25 and total return on capital is 1.077 . The propensity to consume of a retiree is larger than that of a worker and the ratio of two propensity to consume out of wealth is more than one. Out of total financial assets, the workers' share is about $56.8 \%$ and the retirees' share is about $43.2 \%$. The proportion of total tax revenue to GDP is $18.6 \%$, workers' tax burden to pre-tax labor income is about $33 \%$ and the ratio of consumption to post-tax income is 0.973 . 
Table 3: Statistical data on government debt, expenditure, and social security payments

(unit: \% of GDP)

\begin{tabular}{cccc}
\hline \hline Year & $\begin{array}{c}\text { Government debt } \\
\text { to output }(b)\end{array}$ & $\begin{array}{c}\text { Government expenditure } \\
\text { to output }(g)\end{array}$ & $\begin{array}{c}\text { Government's social security } \\
\text { payments to output }(e)\end{array}$ \\
\hline 2016 & 36.0 & 15.35 & 1.42 \\
2017 & 36.0 & 15.07 & 1.48 \\
2-year average & 36.0 & 15.21 & 1.45 \\
\hline \hline
\end{tabular}

Source: 1) Ministry of Economy and Finance. 2) The FY2017 Accounting Analysis Series, National Assembly Budget Office.

Notes: 1) Government expenditure is the sum of mandatory expenditure excluding social security, interest, intergovernmental transfers to local government, other and discretionary expenditure. 2) Government's social security payments include Old-age Pension, Disability Pension, Survivor Pension in the National Pension Scheme and Basic Pension.

Table 4: Steady-state values

\begin{tabular}{|c|c|c|c|c|}
\hline Year & values & $\begin{array}{l}\text { Steady-state } \\
\text { (per capita) }\end{array}$ & $\begin{array}{c}\text { Variables } \\
\text { values per capita }\end{array}$ & Steady-state \\
\hline 1. Capital stock to output & $k$ & 2.10 & & \\
\hline 2. Capital stock per unit of effective labor & $K / X L$ & 3.25 & & \\
\hline 3. Total return on capital & $R$ & 1.077 & & \\
\hline \multirow[t]{2}{*}{ 4. The propensity to consume out of wealth } & $\pi$ & 0.091 & & \\
\hline & $\varepsilon \pi$ & 0.128 & & \\
\hline $\begin{array}{l}\text { 5. Ratio of a retiree's consumption ratio to a } \\
\text { worker's consumption ratio }\end{array}$ & $\varepsilon$ & 1.403 & & \\
\hline 6. Risk adjusted factor & $\Omega$ & 1.063 & & \\
\hline \multirow[t]{2}{*}{ 7. Ratio of human wealth to output } & $h^{w}$ & 2.447 & $h^{w} / q^{w}$ & 3.903 \\
\hline & $h^{r}$ & 0.481 & $h^{r} / q^{r}$ & 1.290 \\
\hline \multirow[t]{2}{*}{ 8. Ratio of social security wealth to output } & $s^{w}$ & 0.075 & $s^{w} / q^{w}$ & 0.120 \\
\hline & $s^{r}$ & 0.106 & $s^{r} / q^{r}$ & 0.284 \\
\hline \multirow[t]{2}{*}{ 9. Share of financial assets } & $\lambda^{w}=1-\lambda^{r}$ & 0.568 & $\lambda^{w} / q^{w}$ & 0.907 \\
\hline & $\lambda^{r}$ & 0.432 & $\lambda^{r} / q^{r}$ & 1.156 \\
\hline 10. Ratio of total tax to output & $\tau$ & 0.186 & & \\
\hline \multirow[t]{3}{*}{ 11. Ratio of consumption to output } & $c^{w}$ & 0.366 & $c^{w} / q^{w}$ & 0.584 \\
\hline & $c^{r}$ & 0.221 & $c^{r} / q^{r}$ & 0.591 \\
\hline & $c=c^{w}+c^{r}$ & 0.587 & & \\
\hline $\begin{array}{l}\text { 12. Ratio of workers' consumption to workers' } \\
\text { after-tax labor income }\end{array}$ & $c^{w} /\left(\alpha \frac{L^{w}}{L}-\tau\right)$ & 0.973 & & \\
\hline 13. Workers' tax burden on labor income & $\tau / \alpha \frac{L^{w}}{L}$ & 0.330 & & \\
\hline \multirow[t]{2}{*}{ 14. Labor supply } & $L^{w} / N$ & 0.506 & & \\
\hline & $L^{r} / N \psi$ & 0.166 & & \\
\hline
\end{tabular}

Note: 1) $w$ denotes workers and $r$ denotes retirees. 2) The proportion of workers $q^{w}=1 /(1+\psi)$ and the proportion of retirees $q^{r}=\psi /(1+\psi)$ are obtained by using the ratio of the number of retirees to the number of workers $\psi$.

In this model, only a worker pays income tax, so the proportion of workers' consumption to their post-tax income is considerably high, showing that they have less room to save for capital accumulation. Workers supply labor, about $50.6 \%$ of their total labor force is in a steady-state. Retirees supply labor about $16.6 \%$ of their total labor force since they have a lower productivity of a unit of labor and lower wages than workers. This then reflects that retirees have more accumulated financial wealth on average.

In the fourth and fifth column of Table 4, we show the steady-state values per capita of each group for easy comparison between groups. The proportion of each group is obtained using the ratio of the number of retirees to the number of workers $\psi$. Of total population, the proportion of workers is $62.7 \%$ and that of retirees is $37.3 \%$, respectively. For the ratio of human assets to output on a per capita basis, per worker is 3.903 and per retiree is 1.290 . A worker has a longer working period and 
Table 5: Effects of an aging on retiree's survival rate and population structure

\begin{tabular}{ccccc}
\hline \hline $\begin{array}{c}\text { Life expectancy } \begin{array}{c}\text { a birth } \\
\text { (unit: years) }\end{array} \\
83\end{array}$ & $\begin{array}{c}\text { Life expectancy } \\
\text { of a retiree } \\
\text { (unit: years) }\end{array}$ & $\begin{array}{c}\text { Retiree's } \\
\text { probability of } \\
\text { survival }(\gamma)\end{array}$ & \multicolumn{2}{c}{ Percentage of each group } \\
\cline { 3 - 5 } 8 & 12 & 0.917 & $62.7 \%$ & Retirees \\
85 & 13 & 0.923 & $61.0 \%$ & $37.3 \%$ \\
86 & 14 & 0.929 & $59.4 \%$ & $40.6 \%$ \\
87 & 15 & 0.933 & $58.0 \%$ & $42.0 \%$ \\
88 & 16 & 0.938 & $56.6 \%$ & $43.4 \%$ \\
89 & 17 & 0.941 & $55.3 \%$ & $44.7 \%$ \\
$\Delta 6$ & 18 & 0.944 & $54.1 \%$ & $45.9 \%$ \\
\hline \hline
\end{tabular}

higher efficiency per unit of labor than a retiree; therefore, so the value of human wealth per worker is also higher than that of a retiree. The share of assets per capita is 0.907 for a worker, 1.156 for a retiree. Financial assets of retirees consist of existing assets and transferred assets from workers in the event of retirement and the share of financial assets per retiree is a higher level compared to that of a worker.

\subsection{Sensitivity analysis}

Population aging is ready to become one of the most important social changes, affecting all sectors of society, including financial and labor markets, demand for goods and services such as social protection, and population structure and intergenerational ties. Governments around the world are discussing the extension of retirement age as one of the countermeasures in response to a rapidly growing aging population. However, legally, extending the retirement age can cause generational conflict or employment conflict between young and old; therefore, it is not easy to realize it in a short period of time in terms of the need for social consensus.

We analyze the impact of aging and retirement age extension on the steady-state economy in two different scenarios. First, the effects of the increase in the life expectancy of retirees, and second, the simultaneous effects of an increase in the life expectancy of retirees and the extension of retirement age.

\subsubsection{Steady-state impact of aging}

According to the latest population projections for Korea published in 2019, life expectancy in South Korea is projected to rise by 8.8 years to 88.5 for males and by 6.0 years to 91.7 for females by 2067 . And total life expectancy is projected to rise by 7.4 years to 90.1 . Reflecting this trend in aging from 83 to 89 , we calculate life expectancy and the survival rate of a representative retiree aged 71 (Table $5)$.

We now analyze the impact of the continuing rise in the life expectancy of retirees on the economy as population aging intensifies. If the life expectancy of retirees increases without an adjustment of the retirement age, it increases relative to the proportion of the retirement population. With a 6-year increase in the life expectancy of a retiree, the probability of survival of retirees increases from 0.917 to 0.944 and the percentage of each group decreases by $8.56 \%$ p for workers and increases by $8.56 \%$ p for retirees. That is, the proportion of workers to total population decreases from $62.7 \%$ to $54.1 \%$ and that of retirees to total population increases from $37.3 \%$ to $45.9 \%$.

Figure 3(a) shows that the social security wealth of both workers and retirees increases because of an increase in social security benefits per capita as well as due to an increased retirement period. The 


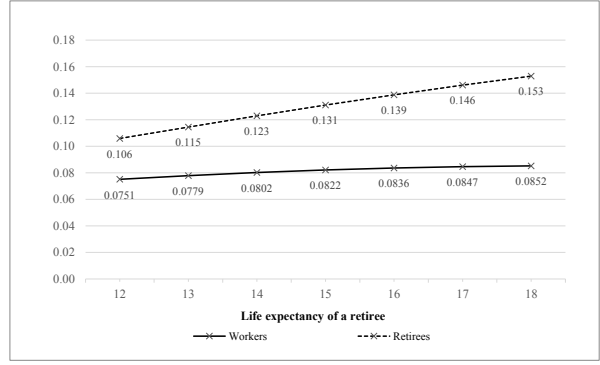

(a) Social security wealth

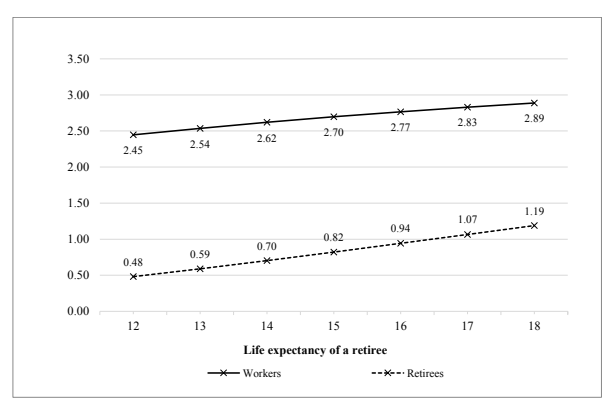

(c) Human wealth

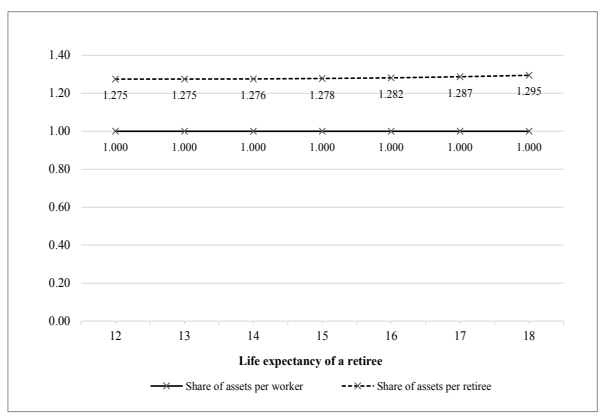

(e) Share of assets per capita

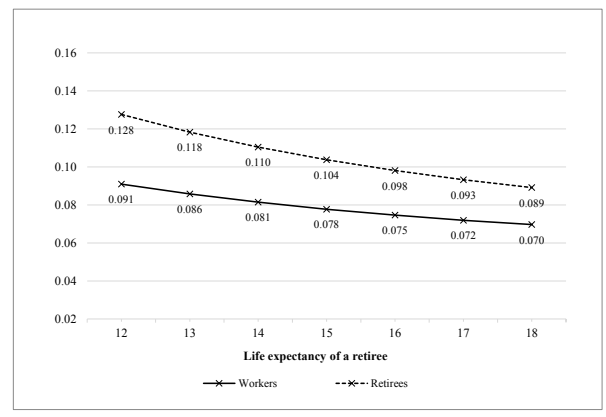

(g) Propensity to consume out of wealth

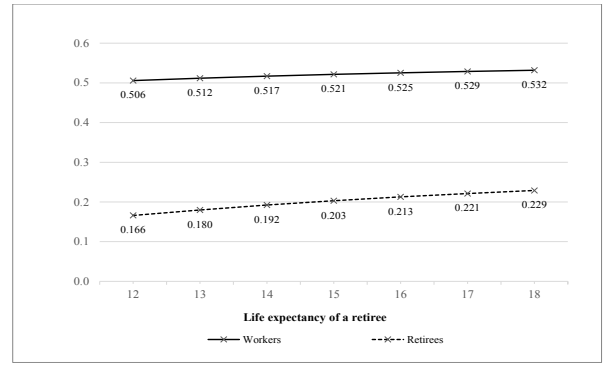

(b) Labor supply

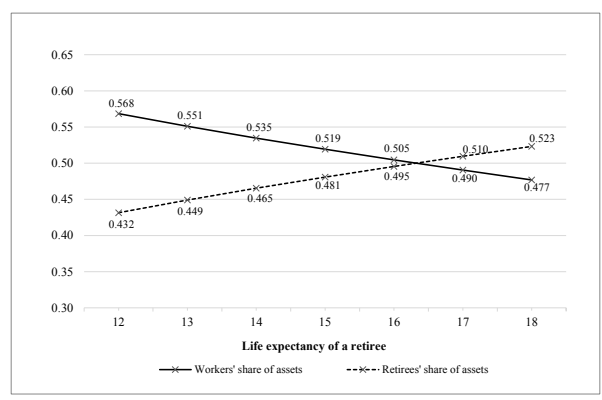

(d) Share of assets

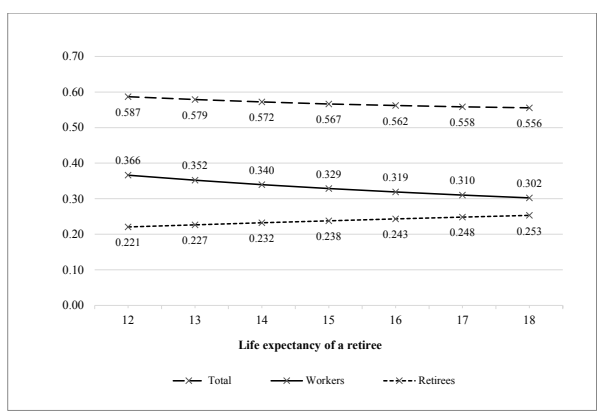

(f) Consumption

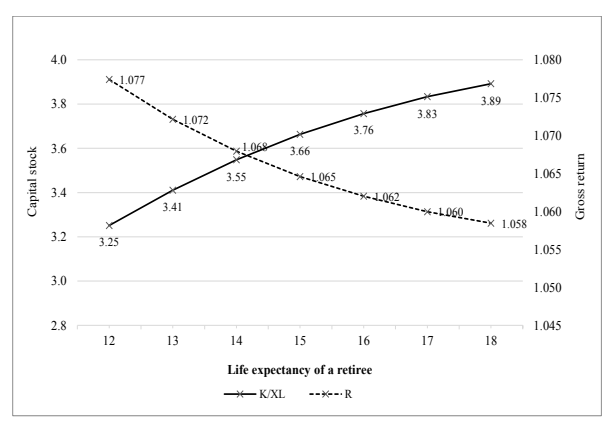

(h) Capital, gross return on capital

Figure 3: Steady-state impact of the life expectancy of retirees. 
Table 6: Retirement ages and expected years in retirement in OECD statistics (unit: years)

\begin{tabular}{|c|c|c|c|c|}
\hline & \multicolumn{2}{|c|}{$\begin{array}{l}\text { Design of pension systems-current retirement ages } \\
\text { for a person who entered the labor force at age } 22\end{array}$} & \multicolumn{2}{|c|}{ Expected years in retirement } \\
\hline & Men & Women & Men & Women \\
\hline Korea (a) & 61.0 & 61.0 & 12.9 & 16.3 \\
\hline OECD-Average (b) & 64.2 & 63.5 & 17.8 & 22.5 \\
\hline (b) $-(a)$ & 3.2 & 2.5 & 4.9 & 6.2 \\
\hline
\end{tabular}

ratio of social security wealth to GDP of workers increases from 0.075 to 0.085 and that of retirees increases from 0.106 to 0.153 .

As individuals live longer, the labor supply of both workers and retirees increase. In Figure 3(b), workers' labor supply increases from $50.6 \%$ to $53.2 \%$ by $5.1 \%$ and retirees' labor supply increases from $16.6 \%$ to $22.9 \%$ by $37.9 \%$ as the life expectancy of a retiree increases by 6 years. Therefore, for both workers and retirees, the ratio of human wealth to GDP also increases (Figure 3(c)). Asset transfers from workers to retirees increase as the proportion of retirees increases. The share of assets for retirees increases more than before, from $43.2 \%$ to $52.3 \%$, while the share of assets for workers decreases from $56.8 \%$ to $47.7 \%$ (Figure 3(d)). However, the share of assets per retiree is maintained at 1.28-1.29 without significant change due to the increase in the number of retirees despite the increase in the total share of assets (Figure 3(e)).

As life expectancy increases, the period of time in retirement becomes longer, which reduces both a worker's and a retiree's propensity to consume out of wealth in preparation for their life after retirement. This leads to a decrease in the percentage of total consumption to GDP from 58.7\% to $55.6 \%$ despite the increase in the ratio of social security wealth and human wealth to GDP (Figures $3(\mathrm{f})$ and $(\mathrm{g}))$. In the same context, an individual's incentive to save for old age leads to a rise in capital stock to GDP from 3.25 to 3.89 and a reduction in gross return on capital from 1.077 to 1.058 (Figure $3(\mathrm{~h}))$.

\subsubsection{Steady-state impact of retirement age extension}

According to OECD statistics in 2019 regarding pension systems, Korea's current retirement age is 3.2 years lower for men and 2.5 years lower for women compared to the OECD average, and expected years in retirement is 4.9 years lower for men and 6.2 years lower for women than the OECD average (Table 6).

The concept of statutory retirement ages and retirement ages in a pension system differ slightly around the world; however, we conduct analyses using these statistics. We assume that Korea's retirement age and the life expectancy of retirees gradually reach half the OECD average since extending the retirement age is a matter of policy decision making, and difficult to realize in a short period of time. Therefore, we assume a scenario in which the retirement age is extended by 1.5 years, 0.25 years per year, while the life expectancy of a retiree is increased by a total of 6 years. Results show that the proportion of retirees increases by $5.70 \%$ p, less than the $8.56 \%$ p increase given the aging effect only (Table 5 and Table 7). Extending the retirement age increases the proportion of workers and reduces that of retirees.

There is still an aging effect even if the statutory retirement age of workers is extended. Therefore, effect on the steady-state of economy is similar to before the retirement age extension. As the aging population progresses, the differences between before and after the policy of retirement age extension is implemented are as follows.

First, variation in the length of working time by the retirement age extension has an alleviation 
Table 7: The simultaneous effects of an aging and a retirement age extension on transition probability and population structure

\begin{tabular}{|c|c|c|c|c|c|c|c|}
\hline \multirow{2}{*}{$\begin{array}{c}\text { Life } \\
\text { expectancy } \\
\text { at birth } \\
\text { (unit: years) }\end{array}$} & \multicolumn{3}{|c|}{ Retirees } & \multicolumn{2}{|c|}{ Workers } & \multicolumn{2}{|c|}{$\%$ of each group } \\
\hline & $\begin{array}{c}\text { Life } \\
\text { expectancy } \\
\text { of a retiree } \\
\text { (unit: years) }\end{array}$ & $\begin{array}{c}\text { Retiree's } \\
\text { probability } \\
\text { of survival } \\
(\gamma)\end{array}$ & $\begin{array}{c}\text { Retirement } \\
\text { age } \\
\text { (unit: years) }\end{array}$ & $\begin{array}{l}\text { Working period } \\
\text { expectancy } \\
\text { of worker } \\
\text { (unit: years) }\end{array}$ & $\begin{array}{c}\text { probability of } \\
\text { remaining } \\
\text { worker next } \\
\text { period }(\omega)\end{array}$ & Workers & Retirees \\
\hline 83 & 12 & $91.67 \%$ & 60.00 & 18.00 & $94.44 \%$ & $62.7 \%$ & $37.3 \%$ \\
\hline 84 & 13 & $92.31 \%$ & 60.25 & 18.25 & $94.52 \%$ & $61.3 \%$ & $38.7 \%$ \\
\hline 85 & 14 & $92.86 \%$ & 60.50 & 18.50 & $94.59 \%$ & $60.1 \%$ & $39.9 \%$ \\
\hline 86 & 15 & $93.33 \%$ & 60.75 & 18.75 & $94.67 \%$ & $59.0 \%$ & $41.0 \%$ \\
\hline 87 & 16 & $93.75 \%$ & 61.00 & 19.00 & $94.74 \%$ & $57.9 \%$ & $42.1 \%$ \\
\hline 88 & 17 & $94.12 \%$ & 61.25 & 19.25 & $94.81 \%$ & $57.0 \%$ & $43.0 \%$ \\
\hline 89 & 18 & $94.44 \%$ & 61.50 & 19.50 & $94.87 \%$ & $56.1 \%$ & $43.9 \%$ \\
\hline$\triangle 6$ & $\triangle 6$ & $\triangle 2.78 \%$ & $\triangle 1.5$ & $\triangle 1.0$ & $\triangle 0.43 \%$ & $\nabla 5.70 \% \mathrm{p}$ & $\triangle 5.70 \% \mathrm{p}$ \\
\hline
\end{tabular}

effect on the variation in labor supply of both workers and retirees. In Figure 4(b), compared to labor supply with only aging effect in Figure 3(b), the increment in labor supply of both workers and retirees is slightly smaller. This is because it is possible to prepare for retirement with less labor due to longer working periods by the retirement extensions at a time in an elastic labor market.

Second, after adjusting the retirement age, even with the same life expectancy, the fluctuation in the share of assets for workers and retirees is smaller. Considering only the aging effect, the retirees' share of assets reverses that of workers when the life expectancy of retirees is 17 years or more (Figure 3(d)). However, after the retirement age is extended, the gap in both share of assets between workers and retirees is smaller than before (Figure 4(d)).

Third, as an effect of extending the retirement age, the fluctuation in the ratio of consumption to GDP is greater than before. The ratio of total consumption to GDP decreases even more after extending the retirement age than when there is only an aging effect in a comparison of Figure 4(f) and Figure 3(f). Workers and retirees increase their leisure time and further reduce consumption with a relatively less increased labor supply compared to when there is only an aging effect as the retirement age is extended. As a result of the working period extension due to retirement age adjustment, capital stock throughout the economy increases from 3.25 to 4.07 which is higher than the steady-state of capital stock when there is only an aging effect (Figure 4(h) and Figure 3(h)).

\section{Conclusions}

This paper is meaningful in that there is a theoretical contribution by providing clear and detailed derivation of economic agents' decision problems including elastic labor supply in Gertler's OLG model. In addition, this study is also meaningful in that a relatively tractable Gertler's OLG model was first used in the analysis of the Korean economy and important social issues facing Korea such as aging along with retirement age extension by calibration and it suggested implications for the economy. Under reasonable parameters, we analyzed the impact on the Korean economy and the behavior of economic agents in a long-term equilibrium by performing social experiments.

The conclusions that can be drawn from this study are as follows. First, as life expectancy increases, the period of time in retirement becomes longer, which reduces a worker's and a retiree's propensity to consume out of wealth in preparation for their life after retirement. This then leads to a decrease in the proportion of total consumption to GDP despite the increase in social security wealth and human wealth to GDP. In the same context, an individual's incentive to save for old age leads to 


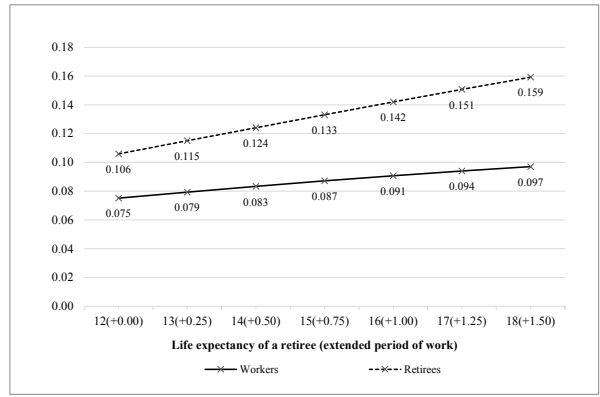

(a) Social security wealth

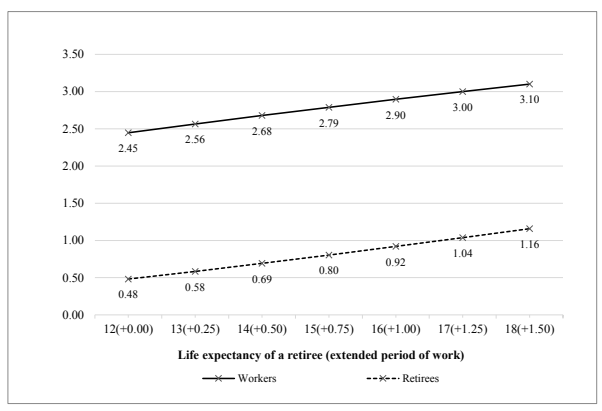

(c) Human wealth

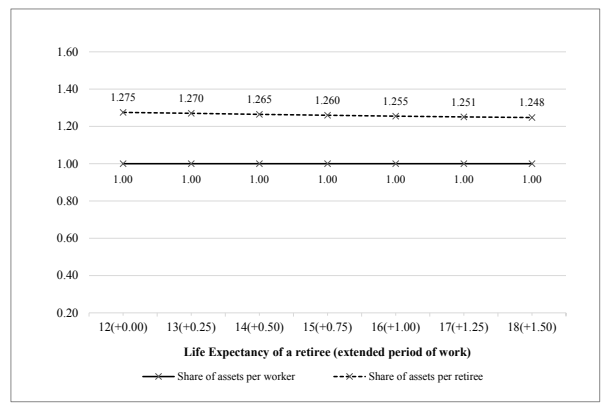

(e) Share of assets per capita

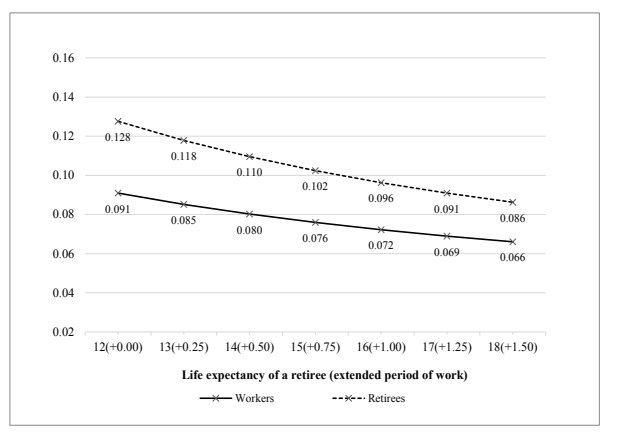

(g) Propensity to consume out of wealth

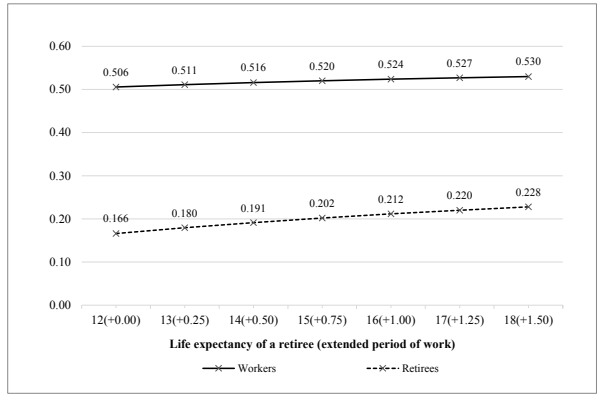

(b) Labor supply

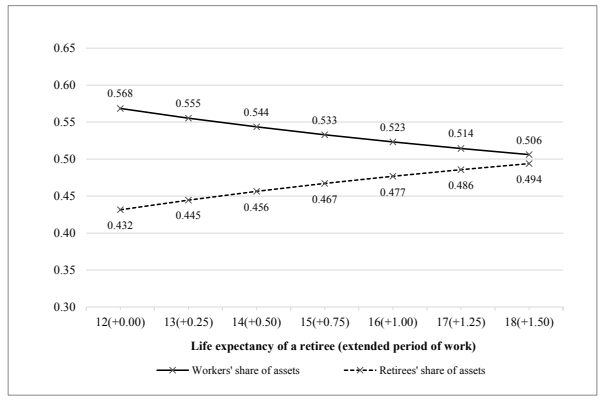

(d) Share of assets

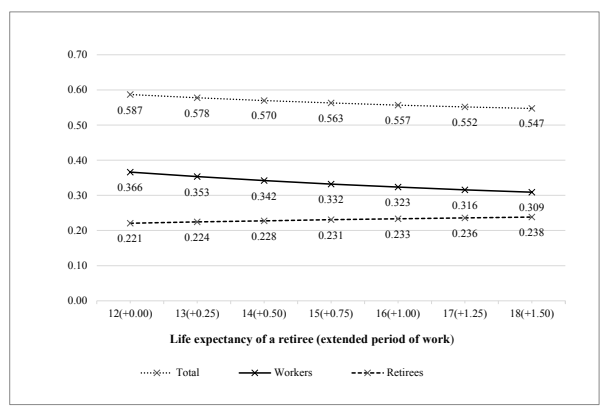

(f) Consumption

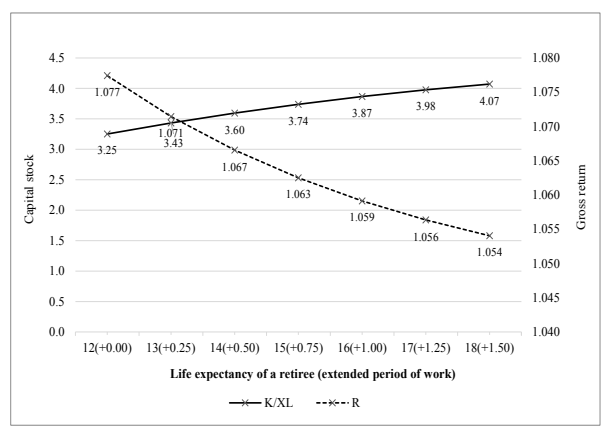

(h) Capital, gross return on capital

Figure 4: Steady-state impact of life expectancy of retirees and retirement age extension. 
a rise in capital stock to GDP and a reduction in gross return on capital. Second, after the retirement age extension policy is implemented, extension of the length of working time has an alleviation effect on the variation in the labor supply of workers and retirees. This is because it is possible to prepare for retirement with less labor due to longer working periods at the time of an elastic labor market. In addition, as the fluctuation in the share of financial assets is smaller, the gap in share of assets per capita between groups is smaller than before. However, the decrease in the ratio of consumption to GDP is greater than before, since workers and retirees increase leisure time and further reduce consumption with a relatively less increased labor supply compared to when there is only an aging effect. Therefore, capital stock throughout the economy increases higher than the steady state of capital stock when there is only an aging effect due to the extension of working period.

Gertler's OLG model is tractable and has usefulness in economic analysis; however, additional problems, remain to be explained. First, it needs to refine two factors in valuations in worker's decision problems because there is an ambiguous step in deriving the risk adjustment factor and the discounting rate used in the valuation of a worker's non-financial assets in transition from work to retirement. Second, it is necessary to generalize Gertler's model in the matter of representative agents' characteristics such as work probability, mortality, subjective discount factor and intertemporal preference. The identical transition probability within each group assumed by Gertler's model needs to be improved for a more practical analysis of the economy. Finally, cross-country analysis using a calibration method should be developed to practically implement the model for economic analysis despite having only performed calibration for the Korean economy in this paper.

\section{Appendix A: Retiree-decision problems}

Maximize

$$
V_{t}^{r}=\left[\left\{\left(C_{t}^{r}\right)^{v}\left(1-l_{t}^{r}\right)^{1-v}\right\}^{\rho}+\beta \gamma\left(V_{t+1}^{r}\right)^{\rho}\right]^{\frac{1}{\rho}}
$$

subject to

$$
A_{t+1}^{r}=\frac{R_{t}}{\gamma} A_{t}^{r}+W_{t}^{r} l_{t}^{r}+E_{t}-C_{t}^{r}
$$

Using Lagrange multiplier $\mu$, the optimization problem can be rewritten as

$$
L=V_{t}^{r}-\mu\left(A_{t+1}^{r}-\frac{R_{t}}{\gamma} A_{t}^{r}-W_{t}^{r} l_{t}^{r}-E_{t}+C_{t}^{r}\right) .
$$

Let us partially differentiate $L$ with respect to $C_{t}^{r}, l_{t}^{r}$, and $A_{t+1}^{r}$. From the three partial derivatives, i.e.

$$
\begin{aligned}
\frac{\partial L}{\partial C_{t}^{r}} & =\left(V_{t}^{r}\right)^{1-\rho} v\left(C_{t}^{r}\right)^{v \rho-1}\left(1-l_{t}^{r}\right)^{(1-v) \rho}-\mu=0, \\
\frac{\partial L}{\partial l_{t}^{r}} & =-\left(V_{t}^{r}\right)^{1-\rho}(1-v)\left(C_{t}^{r}\right)^{v \rho}\left(1-l_{t}^{r}\right)^{(1-v) \rho-1}+\mu W_{t}^{r}=0, \\
\frac{\partial L}{\partial A_{t+1}^{r}} & =\left(V_{t}^{r}\right)^{1-\rho} \beta \gamma \frac{\partial V_{t+1}^{r}}{\partial A_{t+1}^{r}}\left(V_{t+1}^{r}\right)^{\rho-1}-\mu=0
\end{aligned}
$$

we have

$$
1-l_{t}^{r}=\frac{1-v}{v} \frac{C_{t}^{r}}{W_{t}^{r}} .
$$


From (A.4) and (A.6)

$$
\begin{aligned}
v\left(C_{t}^{r}\right)^{v \rho-1}\left(1-l_{t}^{r}\right)^{(1-v) \rho} & =\beta \gamma \frac{\partial V_{t+1}^{r}}{\partial A_{t+1}^{r}}\left(V_{t+1}^{r}\right)^{\rho-1} \\
\mu & =v\left(C_{t}^{r}\right)^{v \rho-1}\left(1-l_{t}^{r}\right)^{(1-v) \rho}\left(V_{t}^{r}\right)^{1-\rho} .
\end{aligned}
$$

Applying the Envelope Theorem with parameter $A_{t}^{r}$,

$$
\frac{d V_{t}^{r}}{d A_{t}^{r}}=\frac{\partial L}{\partial A_{t}^{r}}=\mu \frac{R_{t}}{\gamma}=\frac{R_{t}}{\gamma} v\left(C_{t}^{r}\right)^{v \rho-1}\left(1-l_{t}^{r}\right)^{(1-v) \rho}\left(V_{t}^{r}\right)^{1-\rho} .
$$

From (A.10), we have

$$
\frac{d V_{t+1}^{r}}{d A_{t+1}^{r}}=\frac{R_{t+1}}{\gamma} v\left(C_{t+1}^{r}\right)^{v \rho-1}\left(1-l_{t+1}^{r}\right)^{(1-v) \rho}\left(V_{t+1}^{r}\right)^{1-\rho} .
$$

Let us guess the form of $V_{t}^{r}$

$$
V_{t}^{r}=\left(\varepsilon_{t} \pi_{t}\right)^{-\frac{1}{\rho}}\left(C_{t}^{r}\right)^{v}\left(1-l_{t}^{r}\right)^{1-v}
$$

and plug (A.7) in (A.12)

$$
V_{t}^{r}=\left(\varepsilon_{t} \pi_{t}\right)^{-\frac{1}{\rho}} C_{t}^{r}\left(\frac{1-v}{v W_{t}^{r}}\right)^{1-v}
$$

From (A.13), we have

$$
V_{t+1}^{r}=\left(\varepsilon_{t+1} \pi_{t+1}\right)^{-\frac{1}{\rho}} C_{t+1}^{r}\left(\frac{1-v}{v W_{t+1}^{r}}\right)^{1-v} .
$$

Placing (A.11), (A.14) into (A.8)

$$
v\left(C_{t}^{r}\right)^{\rho-1}\left(\frac{1-v}{v W_{t}^{r}}\right)^{(1-v) \rho}=\beta R_{t+1} v\left(\frac{1-v}{v W_{t+1}^{r}}\right)^{1-v}\left[C_{t+1}^{r}\left(\frac{1-v}{v W_{t+1}^{r}}\right)^{1-v}\right]^{\rho-1} .
$$

which is rewritten as

$$
\left(C_{t+1}^{r}\right)^{1-\rho}=\left(\frac{W_{t}^{r}}{W_{t+1}^{r}}\right)^{(1-v) \rho} R_{t+1} \beta\left(C_{t}^{r}\right)^{1-\rho}
$$

or

$$
C_{t+1}^{r}=\left[\left(\frac{W_{t}^{r}}{W_{t+1}^{r}}\right)^{(1-v) \rho} R_{t+1} \beta\right]^{\sigma} C_{t}^{r},
$$

where $\sigma=1 /(1-\rho)$ and $W_{t}^{r}=\xi W_{t}$.

Next, let us guess a solution of the form:

$$
C_{t}^{r}=\varepsilon_{t} \pi_{t}\left(\frac{R_{t}}{\gamma} A_{t}^{r}+H_{t}^{r}+S_{t}^{r}\right)
$$


Rederivation of Gertler's model and analysis of the Korean economy

669

Check that

$$
C_{t+1}^{r}=\varepsilon_{t+1} \pi_{t+1}\left(\frac{R_{t+1}}{\gamma} A_{t+1}^{r}+H_{t+1}^{r}+S_{t+1}^{r}\right) .
$$

Placing (A.18), (A.19) into (A.17), we can obtain

$$
\varepsilon_{t+1} \pi_{t+1}\left(\frac{R_{t+1}}{\gamma} A_{t+1}^{r}+H_{t+1}^{r}+S_{t+1}^{r}\right)=\left[\left(\frac{W_{t}^{r}}{W_{t+1}^{r}}\right)^{(1-v) \rho} R_{t+1} \beta\right]^{\sigma} \varepsilon_{t} \pi_{t}\left(\frac{R_{t}}{\gamma} A_{t}^{r}+H_{t}^{r}+S_{t}^{r}\right) .
$$

Now, substituting (A.13), (A.14) into value function (A.1), and replacing $C_{t+1}^{r}$ to the form of $C_{t}^{r}$ using the relation (A.17), then we obtain

$$
\begin{aligned}
& {\left[\left(\varepsilon_{t} \pi_{t}\right)^{-\frac{1}{\rho}} C_{t}^{r}\left(\frac{1-v}{v W_{t}^{r}}\right)^{1-v}\right]^{\rho}} \\
& =\left[C_{t}^{r}\left(\frac{1-v}{v W_{t}^{r}}\right)^{1-v}\right]^{\rho}+\beta \gamma\left[\left(\varepsilon_{t+1} \pi_{t+1}\right)^{-\frac{1}{\rho}}\left(\left(\frac{W_{t}^{r}}{W_{t+1}^{r}}\right)^{(1-v) \rho} R_{t+1} \beta\right)^{\sigma} C_{t}^{r}\left(\frac{1-v}{v W_{t+1}^{r}}\right)^{1-v}\right]^{\rho},
\end{aligned}
$$

which can be written as

$$
\left(\varepsilon_{t} \pi_{t}\right)^{-1}=1+\left[\left(\frac{W_{t}^{r}}{W_{t+1}^{r}}\right)^{1-v} R_{t+1}\right]^{\sigma-1} \beta^{\sigma} \gamma\left(\varepsilon_{t+1} \pi_{t+1}\right)^{-1}
$$

or

$$
\varepsilon_{t} \pi_{t}=1-\left[\left(\frac{W_{t}^{r}}{W_{t+1}^{r}}\right)^{1-v} R_{t+1}\right]^{\sigma-1} \beta^{\sigma} \gamma \frac{\varepsilon_{t} \pi_{t}}{\varepsilon_{t+1} \pi_{t+1}}
$$

From (A.23), we have

$$
\varepsilon_{t+1} \pi_{t+1}=\left[\left(\frac{W_{t}^{r}}{W_{t+1}^{r}}\right)^{1-v} R_{t+1}\right]^{\sigma-1} \beta^{\sigma} \gamma \frac{\varepsilon_{t} \pi_{t}}{1-\varepsilon_{t} \pi_{t}} .
$$

To confirm a solution for the value function, conjecture that

$$
V_{t}^{r}=\Delta_{t}^{r}\left(C_{t}^{r}\right)^{v}\left(1-l_{t}^{r}\right)^{1-v}=\Delta_{t}^{r}\left(C_{t}^{r}\right)^{v}\left(\frac{1-v}{v W_{t}^{r}}\right)^{1-v} .
$$

Then, to obtain an expression for $\Delta_{t}^{r}$, substitute the conjectured solution for $V_{t}^{r}$ into the objective to obtain

$$
\Delta_{t}^{r} C_{t}^{r}\left(\frac{1-v}{v W_{t}^{r}}\right)^{1-v}=\left[\left\{C_{t}^{r}\left(\frac{1-v}{v W_{t}^{r}}\right)^{1-v}\right\}^{\rho}+\beta \gamma\left\{\Delta_{t+1}^{r} C_{t+1}^{r}\left(\frac{1-v}{v W_{t+1}^{r}}\right)^{1-v}\right\}^{\rho}\right]^{\frac{1}{\rho}} .
$$

Here, placing (A.17) into (A.26), (A.26) can be rewritten as

$$
\left\{\Delta_{t}^{r} C_{t}^{r}\left(\frac{1-v}{v W_{t}^{r}}\right)^{1-v}\right\}^{\rho}=\left\{C_{t}^{r}\left(\frac{1-v}{v W_{t}^{r}}\right)^{1-v}\right\}^{\rho}+\beta \gamma\left[\Delta_{t+1}^{r}\left\{\left(\frac{W_{t}^{r}}{W_{t+1}^{r}}\right)^{(1-v) \rho} R_{t+1} \beta\right\}^{\sigma} C_{t}^{r}\left(\frac{1-v}{v W_{t+1}^{r}}\right)^{1-v}\right]^{\rho} .
$$


Therefore, applying that $\sigma \rho+1=\sigma$ and $\sigma \rho=\sigma-1$, we have

$$
\left(\Delta_{t}^{r}\right)^{\rho}=1+\left[\left(\frac{W_{t}^{r}}{W_{t+1}^{r}}\right)^{(1-v)} R_{t+1}\right]^{\sigma-1} \beta^{\sigma} \gamma\left(\Delta_{t+1}^{r}\right)^{\rho} .
$$

Now, checking that (A.28) is identical to (A.22), we obtain

$$
\Delta_{t}^{r}=\left(\varepsilon_{t} \pi_{t}\right)^{-\frac{1}{\rho}} .
$$

Therefore,

$$
V_{t}^{r}=\left(\varepsilon_{t} \pi_{t}\right)^{-\frac{1}{\rho}} C_{t}^{r}\left(\frac{1-v}{v W_{t}^{r}}\right)^{1-v}
$$

\section{Appendix B: Worker-decision problems}

Maximize

$$
V_{t}^{w}=\left[\left\{\left(C_{t}^{w}\right)^{v}\left(1-l_{t}^{w}\right)^{1-v}\right\}^{\rho}+\beta\left\{\omega V_{t+1}^{w}+(1-\omega) V_{t+1}^{r}\right\}^{\rho}\right]^{\frac{1}{\rho}}
$$

subject to

$$
A_{t+1}^{w}=R_{t} A_{t}^{w}+W_{t} l_{t}^{w}-C_{t}^{w}
$$

where $W_{t}$ is after-tax wage.

Using Lagrange multiplier $\mu$, the optimization problem can be written as

$$
L=V_{t}^{w}-\mu\left(C_{t}^{w}+A_{t+1}^{w}-R_{t} A_{t}^{w}-W_{t} l_{t}^{w}\right)
$$

Let us partially differentiate $L$ with respect to $C_{t}^{w}, l_{t}^{w}$, and $A_{t+1}^{w}$. From the three partial derivatives, i.e.

$$
\begin{aligned}
\frac{\partial L}{\partial C_{t}^{w}} & =\left(V_{t}^{w}\right)^{1-\rho} v\left(C_{t}^{w}\right)^{v \rho-1}\left(1-l_{t}^{w}\right)^{(1-v) \rho}-\mu=0, \\
\frac{\partial L}{\partial l_{t}^{w}} & =-\left(V_{t}^{w}\right)^{1-\rho}(1-v)\left(C_{t}^{w}\right)^{v \rho}\left(1-l_{t}^{w}\right)^{(1-v) \rho-1}+\mu W_{t}=0, \\
\frac{\partial L}{\partial A_{t+1}^{w}} & =\left(V_{t}^{w}\right)^{1-\rho}\left[\omega V_{t+1}^{w}+(1-\omega) V_{t+1}^{r}\right]^{\rho-1} \beta\left(\omega \frac{\partial V_{t+1}^{w}}{\partial A_{t+1}^{w}}+(1-\omega) \frac{\partial V_{t+1}^{r}}{\partial A_{t+1}^{r}}\right)-\mu=0
\end{aligned}
$$

we have

$$
1-l_{t}^{w}=\frac{1-v}{v} \frac{C_{t}^{w}}{W_{t}}
$$

From (B.4) and (B.6)

$$
\begin{aligned}
v\left(C_{t}^{w}\right)^{v \rho-1}\left(1-l_{t}^{w}\right)^{(1-v) \rho} & =\left[\omega V_{t+1}^{w}+(1-\omega) V_{t+1}^{r}\right]^{\rho-1} \beta\left(\omega \frac{\partial V_{t+1}^{w}}{\partial A_{t+1}^{w}}+(1-\omega) \frac{\partial V_{t+1}^{r}}{\partial A_{t+1}^{r}}\right) \\
\mu & =v\left(C_{t}^{w}\right)^{v \rho-1}\left(1-l_{t}^{w}\right)^{(1-v) \rho}\left(V_{t}^{w}\right)^{1-\rho}
\end{aligned}
$$


Applying the Envelope Theorem with parameter $A_{t}^{w}$,

$$
\frac{d V_{t}^{w}}{d A_{t}^{w}}=\frac{\partial L}{\partial A_{t}^{w}}=\mu R_{t}=v\left(C_{t}^{w}\right)^{v \rho-1}\left(1-l_{t}^{w}\right)^{(1-v) \rho}\left(V_{t}^{w}\right)^{1-\rho} R_{t}
$$

From (B.10), we have

$$
\frac{\partial V_{t+1}^{w}}{\partial A_{t+1}^{w}}=v\left(C_{t+1}^{w}\right)^{v \rho-1}\left(1-l_{t+1}^{w}\right)^{(1-v) \rho}\left(V_{t+1}^{w}\right)^{1-\rho} R_{t+1} .
$$

Let us guess the form of $V_{t}^{w}$ is analogous to the form of $V_{t}^{r}$ and plug (B.7) in (B.12), then

$$
V_{t}^{w}=\left(\pi_{t}\right)^{-\frac{1}{\rho}}\left(C_{t}^{w}\right)^{v}\left(1-l_{t}^{w}\right)^{1-v}=\left(\pi_{t}\right)^{-\frac{1}{\rho}} C_{t}^{w}\left(\frac{1-v}{v W_{t}}\right)^{1-v} .
$$

From (B.12) we have Let us guess the form of $V_{t}^{w}$ is analogous to the form of $V_{t}^{r}$ and plug (B.7) in (B.12), then

$$
V_{t+1}^{w}=\left(\pi_{t+1}\right)^{-\frac{1}{\rho}} C_{t+1}^{w}\left(\frac{1-v}{v W_{t+1}}\right)^{1-v}
$$

Note that

$$
\frac{d V_{t+1}^{j}}{d A_{t+1}^{j}}=v\left(C_{t+1}^{j}\right)^{v \rho-1}\left(1-l_{t+1}^{j}\right)^{(1-v) \rho}\left(V_{t+1}^{j}\right)^{1-\rho} R_{t+1}, \quad \text { for } j=w, r .
$$

Placing (A.13), (B.13) and (B.14) into (B.8), then,

$$
\begin{aligned}
v\left(C_{t}^{w}\right)^{\rho-1}\left(\frac{1}{W_{t}}\right)^{(1-v) \rho}= & {\left[\left(\frac{1-v}{W_{t+1}}\right)^{1-v}\right]^{\rho-1}\left[\omega\left(\pi_{t+1}\right)^{-\frac{1}{\rho}} C_{t+1}^{w}+(1-\omega)\left(\varepsilon_{t+1} \pi_{t+1}\right)^{-\frac{1}{\rho}} C_{t+1}^{r}\left(\frac{W_{t+1}}{W_{t+1}^{r}}\right)^{1-v}\right]^{\rho-1} } \\
& \times \beta R_{t+1} v\left(\frac{1-v}{W_{t+1}}\right)^{1-v}\left[\omega\left(\pi_{t+1}\right)^{-\frac{1-\rho}{\rho}}+(1-\omega)\left(\frac{W_{t+1}}{W_{t+1}^{r}}\right)^{1-v}\left(\varepsilon_{t+1} \pi_{t+1}\right)^{-\frac{1-\rho}{\rho}}\right] . \quad(\mathrm{B} .
\end{aligned}
$$

Simplify the (B.15)

$$
\begin{aligned}
\left(C_{t}^{w}\right)^{\rho-1}= & \left(\frac{W_{t}}{W_{t+1}}\right)^{(1-v) \rho}\left[\omega C_{t+1}^{w}+(1-\omega)\left(\varepsilon_{t+1}\right)^{-\frac{1}{\rho}} C_{t+1}^{r}\left(\frac{W_{t+1}}{W_{t+1}^{r}}\right)^{1-v}\right]^{\rho-1} \\
& \times \beta R_{t+1}\left[\omega+(1-\omega)\left(\frac{W_{t+1}}{W_{t+1}^{r}}\right)^{1-v}\left(\varepsilon_{t+1}\right)^{-\frac{1-\rho}{\rho}}\right]
\end{aligned}
$$

Let us define that $\xi=W_{t+1}^{r} / W_{t+1}, \chi=(1 / \xi)^{1-v}$, and $\sigma=1 /(1-\rho)$

$$
\Omega_{t+1}=\omega+(1-\omega)\left(\varepsilon_{t+1}\right)^{\frac{1}{1-\sigma}} \chi .
$$

Then, (B.17) is rewritten as

$$
\omega C_{t+1}^{w}+(1-\omega) \chi\left(\varepsilon_{t+1}\right)^{\frac{\sigma}{1-\sigma}} C_{t+1}^{r}=\left[\left(\frac{W_{t}}{W_{t+1}}\right)^{1-v}\right]^{\sigma-1}\left(R_{t+1} \Omega_{t+1} \beta\right)^{\sigma} C_{t}^{w}
$$


Now, let us guess a consumption solution of the form:

$$
\begin{aligned}
C_{t}^{w} & =\pi_{t}\left(R_{t} A_{t}^{w}+H_{t}^{w}+S_{t}^{w}\right), \\
C_{t+1}^{w} & =\pi_{t+1}\left(R_{t+1} A_{t+1}^{w}+H_{t+1}^{w}+S_{t+1}^{w}\right) .
\end{aligned}
$$

Applying (B.19), (B.20), (A.19) to (B.18), then we have

$$
\begin{aligned}
& \pi_{t+1}\left[\omega\left(R_{t+1} A_{t+1}^{w}+H_{t+1}^{w}+S_{t+1}^{w}\right)+(1-\omega)\left(\varepsilon_{t+1}\right)^{\frac{1}{1-\sigma}} \chi\left(\frac{R_{t+1}}{\gamma} A_{t+1}^{r}+H_{t+1}^{r}+S_{t+1}^{r}\right)\right] \\
& =\left[\left(\frac{W_{t}}{W_{t+1}}\right)^{1-v}\right]^{\sigma-1}\left(R_{t+1} \Omega_{t+1} \beta\right)^{\sigma} \pi_{t}\left(R_{t} A_{t}^{w}+H_{t}^{w}+S_{t}^{w}\right) .
\end{aligned}
$$

Now, placing (B.13), (A.14) into value function (B.1), we obtain

$$
\begin{aligned}
& {\left[\left(\pi_{t}\right)^{-\frac{1}{\rho}} C_{t}^{w}\left(\frac{1-v}{v W_{t}}\right)^{1-v}\right]^{\rho}} \\
& =\left[C_{t}^{w}\left(\frac{1-v}{v W_{t}}\right)^{1-v}\right]^{\rho}+\beta\left[\omega\left(\pi_{t+1}\right)^{-\frac{1}{\rho}} C_{t+1}^{w}\left(\frac{1-v}{v W_{t+1}}\right)^{1-v}+(1-\omega)\left(\varepsilon_{t+1} \pi_{t+1}\right)^{-\frac{1}{\rho}} C_{t+1}^{r}\left(\frac{1-v}{v W_{t+1}^{r}}\right)^{1-v}\right]^{\rho},
\end{aligned}
$$

which can be written as

$$
\left(\pi_{t}\right)^{-1}=1+\beta\left\{\left(\frac{W_{t}}{W_{t+1}}\right)^{1-v} \frac{\omega C_{t+1}^{w}+(1-\omega) \chi\left(\varepsilon_{t+1}\right)^{\frac{\sigma}{1-\sigma}} C_{t+1}^{r}}{C_{t}^{w}}\right\}^{\frac{\sigma-1}{\sigma}}\left(\pi_{t+1}\right)^{-1},
$$

and placing (B.18) into (B.23). Hence, we have

$$
\pi_{t}=1-\left[\left(\frac{W_{t}}{W_{t+1}}\right)^{1-v} R_{t+1} \Omega_{t+1}\right]^{\sigma-1} \beta^{\sigma}\left(\frac{\pi_{t}}{\pi_{t+1}}\right) .
$$

From (B.24), we have

$$
\pi_{t+1}=\left[\left(\frac{W_{t}}{W_{t+1}}\right)^{1-\nu} R_{t+1} \Omega_{t+1}\right]^{\sigma-1} \beta^{\sigma}\left(\frac{\pi_{t}}{1-\pi_{t}}\right) .
$$

To confirm a solution for the value function, conjecture that

$$
V_{t}^{w}=\Delta_{t}^{w}\left(C_{t}^{w}\right)^{v}\left(1-l_{t}^{w}\right)^{1-v}=\Delta_{t}^{w}\left(C_{t}^{w}\right)^{v}\left(\frac{1-v}{v W_{t}}\right)^{1-v} .
$$

Then, to obtain an expression for $\Delta_{t}^{w}$, substitute the conjectured solution for $V_{t}^{w}$ into the objective to obtain

$$
\begin{aligned}
& \Delta_{t}^{w} C_{t}^{w}\left(\frac{1-v}{v W_{t}}\right)^{1-v} \\
& =\left[\left(C_{t}^{w}\left(\frac{1-v}{v W_{t}}\right)^{1-v}\right)^{\rho}+\beta\left\{\omega \Delta_{t+1}^{w} C_{t+1}^{w}\left(\frac{1-v}{v W_{t+1}}\right)^{1-v}+(1-\omega) \Delta_{t+1}^{r} C_{t+1}^{r}\left(\frac{1-v}{v W_{t+1}^{r}}\right)^{1-v}\right\}^{\rho}\right]^{\frac{1}{\rho}}
\end{aligned}
$$


Here, placing (B.18) into (B.27), (B.27) can be rewritten as

$$
\left(\Delta_{t}^{w} C_{t}^{w}\left(\frac{1-v}{v W_{t}}\right)^{1-v}\right)^{\rho}=\left(C_{t}^{w}\left(\frac{1-v}{v W_{t}}\right)^{1-v}\right)^{\rho}+\beta\left[\Delta_{t+1}^{w}\left\{\left(\frac{W_{t}}{W_{t+1}}\right)^{(1-v) \rho} R_{t+1} \Omega_{t+1} \beta\right\}^{\sigma} C_{t}^{w}\left(\frac{1-v}{v W_{t+1}}\right)^{1-v}\right]^{\rho} .
$$

Therefore, applying that $\sigma \rho+1=\sigma$ and $\sigma \rho=\sigma-1$, we have

$$
\left(\Delta_{t}^{w}\right)^{\rho}=1+\left[\left(\frac{W_{t}}{W_{t+1}}\right)^{1-v} R_{t+1} \Omega_{t+1}\right]^{\sigma-1} \beta^{\sigma}\left(\Delta_{t+1}^{w}\right)^{\rho} .
$$

Now, checking that (B.29) is identical to (B.25), we obtain

$$
\Delta_{t}^{w}=\left(\pi_{t}\right)^{-\frac{1}{\rho}}
$$

Therefore,

$$
V_{t}^{w}=\left(\pi_{t}\right)^{-\frac{1}{\rho}} C_{t}^{w}\left(\frac{1-v}{v W_{t}}\right)^{1-v}
$$

\section{References}

Blanchard OJ (1985). Debt, deficits, and finite horizons, Journal of Political Economy, 93, 223-247. Diamond PA (1965). National debt in a neoclassical growth model, The American Economic Review, $\mathbf{5 5}, 1126-1150$.

Farmer R (1990). RINCE preferences, The Quarterly Journal of Economics, 105, 43-60.

Gertler M (1999). Government debt and social security in a life-cycle economy, Carnegie-Rochester Conference Series on Public Policy, 50, 61-110.

Grafenhofer D, Jaag C, Keuschnigg C, and Keuschnigg M (2006). Probabilistic aging, CESifo Working Paper Series No. 1680, University of St. Gallen Economics Discussion Paper No. 8.

Keuschnigg C and Keuschnigg M (2004). Aging, labor markets, and pension reform in Austria, FinanzArchiv: Public Finance Analysis, 60, 359-392.

Kilponen J, Kinnunen H, and Ripatti A (2006). Population aging in a small open economy: some policy experiments with tractable general equilibrium model, Bank of Finland Research Discussion Paper No. 28/2006, Available from: https://dx.doi.org/10.2139/ssrn.1018328

Rahman M (2008). Demographic uncertainty and welfare in a life-cycle model under alternative public pension systems, CAEPR Working Paper No. 2008-024, Available from: http://dx.doi.org/10. 2139/ssrn.1270643

Weil P (1989). Overlapping families of infinitely lived agents, Journal of Public Economics, 38, $183-198$.

Yaari ME (1965). Uncertain lifetime, life insurance, and the theory of the consumer, Review of Economic Studies, 32, 137-150. 